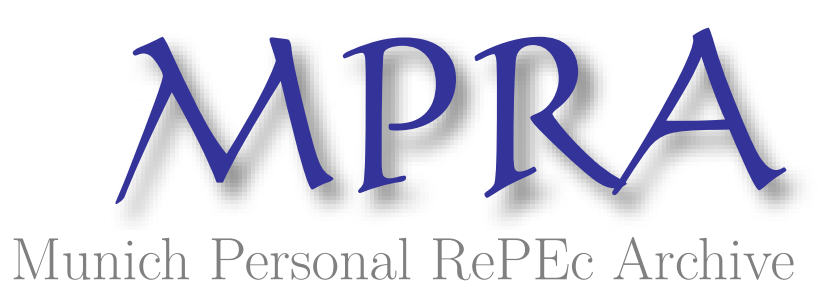

\title{
A Simulation of the Illegal Coal Mining in Quang Ninh Province, Vietnam using Vensim
}

Phan, Tuan

6 June 2008

Online at https://mpra.ub.uni-muenchen.de/54068/

MPRA Paper No. 54068, posted 06 Mar 2014 14:22 UTC 


\title{
A SIMULATION OF THE ILLEGAL COAL MINING IN QUANG NINH PROVINCE, VIETNAM USING VENSIM
}

\author{
Tuan Phan \\ (Hanoi Customs Department, email: tuan.phan@anu.edu.au)
}

This version: June 2008

\begin{abstract}
Using Vensim PLE, this paper provides a simulation of the illegal coal mining in Quang Ninh province, Vietnam. Examining the three main loops including need for income effect, government enforcement and coal management effects and other effects (illegal density, technology, community and psychological effects), the paper sketches several scenarios under different levels of the key variables. Obtaining these results, the paper suggests a better scene in terms of socio-economic and environmental sustainability basing on the two major components. First, the government authorities should urge the enforcement and revise the coal management. Second, the community should have more active activities to abolish the illegal mining trend and raise effectively warnings about the danger of the illegal mining. Those parallel implementations shall create a surprisingly positive effect on the reduction of illegal coal mining in the province.
\end{abstract}

Key words: illegal coal mining, simulation, Vietnam

JEL classification: Q32, Q38 


\section{Introduction}

Coal is considered a non-renewable resource, which is necessary for thermo electricity and many other heavy industries, such as metallurgy and cement. Coal mining is usually implemented by governments or authorized mining corporations. Recently, the illegal coal mining in Quang Ninh province - the main coal mining area in Vietnam - has become a highlight in terms of the serious level, which forces local and central government revise their policy on coal mining.

The total coal reserves in Vietnam are about 220 billion tons (Coal and Mineral Corporation 2007), in which about 210 billion tons are in the Red river delta. However, most of the reserves are beneath 3500 meter depth, hence costs for mining would be very huge in case of exploitation. The most economic area is Quang Ninh province, where 10.5 billion tons of coal are mainly open-cast or below 300 meter depth. Nevertheless, the coal in this province has been exploited for about 100 years (from the French colonies period), with average amount of 40 million tons per year. Therefore, by now the reserves remain about 6.5 billion tons.

The coal exploitation in Quang Ninh province was assigned to the Vietnam Coal and Mineral Corporation, a state own enterprise which was established in 1994 under the old name Vietnam Coal Corporation. In 2007, total mining amount of the corporation was 40 million tons, including 15 million tons sold domestically (mainly to Vietnam Electricity Corporation, Vietnam Cement Corporation, some steel processing enterprises, fertilizer, chemical and firebrick plants) and 25 million tons exported mainly to Japan and China. However, within the 
same year, an amount of about 10 million tons was illegally mined and sold to China through border. This led to a total loss of government revenue of 4,500 billion Vietnam Dong (equivalent to 300 million US dollars). It turned out that the loss has been incurred for several years. Therefore, the local and central government must take some revisions to prevent the continuing big loss.

The purpose of this paper is to generalize the current status of the illegal mining in Quang Ninh province in order to provide a simulation of these illegal minings. Using Vensim software (copyrighted by Ventana Systems Inc.), we analyze the illegal mining in the area through some conceptual models and a quantified system dynamics model. The simulation is a good measure to describe a clear understanding on the factual situation. In addition, it simultaneously provides some possible scenarios in terms of effects, which come from income need, government's enforcement and coal management, community and other effects.

The method of using Vensim to illustrate environmental activities is employed broadly by researchers. The closest paper is by Dudley (2004), in which he examines the illegal logging in Indonesia. Through causal loops and quantitative models, he analyzes the factors affect local villagers to engage in illegal logging activities and sketches out some possibilities basing on effects from community rights on the willingness of villagers to work illegally. A system dynamics model is also used by Chen et al. (2004) to set up the regional man - land relationship of Xiangfan, Hubei province, China, in which they simulate behaviors of economy and society in the scene of facing an environmental catastrophe. Similarly, Fernandez et al. (2005) use Vensim to simulate aquatic bird reactions as bioindicators of changes in nutrients and bionetwork decline in the Mar Menor lagoon, Spain. 
Nevertheless, simulations have rarely been employed in other types of illegal activities in environmental fields. This paper is the first to apply those kinds of models in investigating the facts happening in Quang Ninh province in terms of illegal coal mining. The results indicate that meanwhile the need for income was the inside motive power to drive local residents and labor from other provinces to engage in illegal mining, the authorities' enforcement and management play the key role in preventing an early collapse of the resource. In addition, community effects should be raised to protect the economic, social and environmental benefits which are deteriorated by illegal exploitation.

The remainder of the paper is divided into three sections. Section 2 is some context background and a brief description of the methods used in the paper. Detailed conceptual and quantified models are constructed in Section 3. Section 4 contains the simulation results and some discussion, including possible scenarios to the coal stock. Section 5 is a conclusion, including some analysis on the limitations of the models used and policy implication.

\section{Context background and methodology}

Quang Ninh is the north-eastern bordered province of Vietnam, within north latitude $20^{\circ} 40^{\prime}$ and $21^{\circ} 40^{\prime}$, east longitude $106^{0} 20^{\prime}$ and $108^{\circ}$. With a surface area of $5900 \mathrm{~km}^{2}$ and population of $1,050,000$, the province has one city, three towns and 10 districts. As introduced in the first section, Quang Ninh province is the main area of coal mining in the country. Coal mines chain is $150 \mathrm{~km}$ long extending from Ke Bao Island (Van Don district) to Mao Khe (Dong Trieu 
district). Quang Ninh pit-coal belongs to the anthracite type, which is hardened with stable carbon content of $80-90$ per cent, and high calorie of 7,350-8,200 Kcal/kg. There are three main coal exploitation areas: Hon Gai, Cam Pha - Duong Huy and Uong Bi - Mao Khe.

\section{Figure 1 Map of Vietnam (and Quang Ninh province's position)}

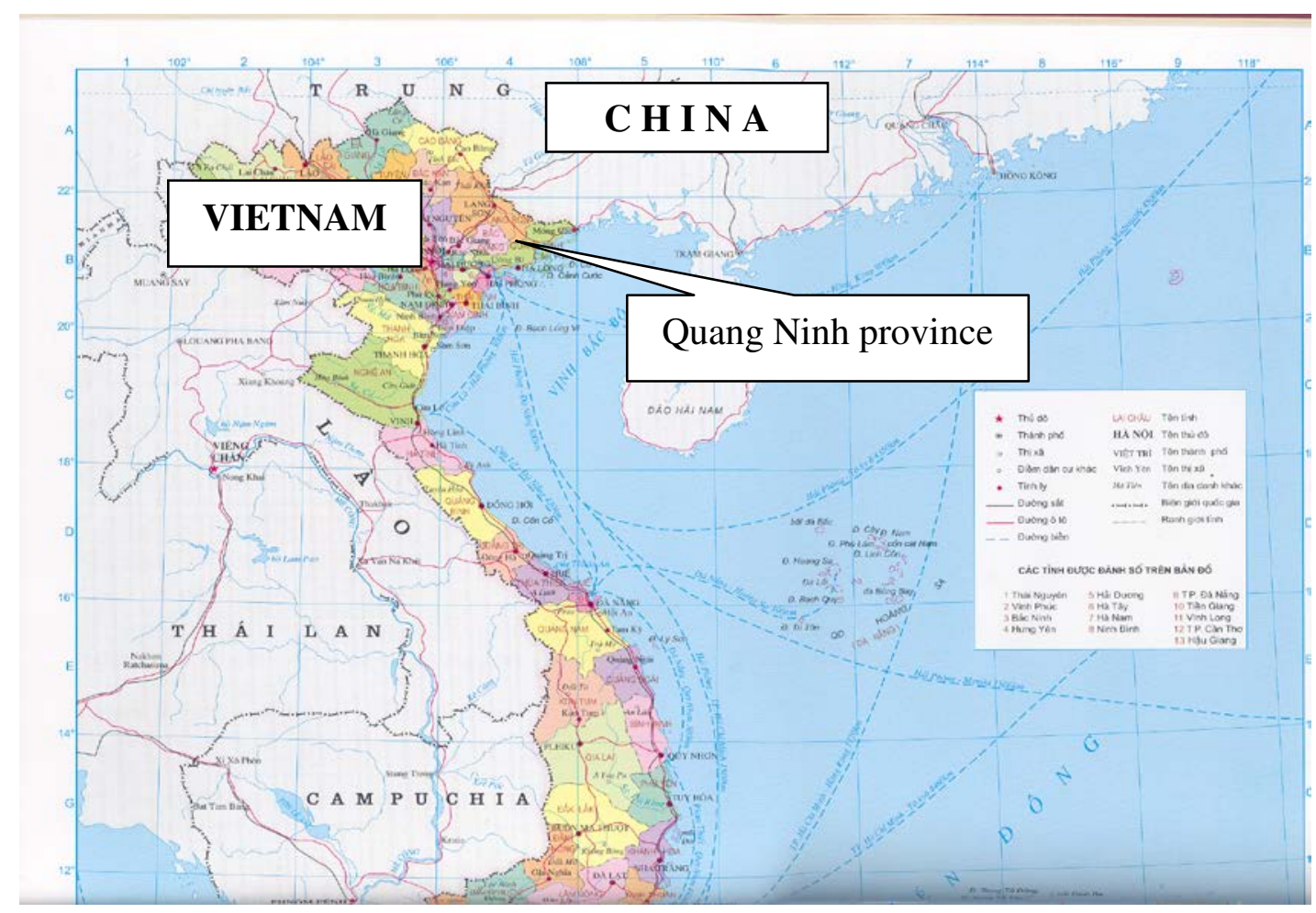

Source: Cartographic Publishing House, 2005. Vietnam Administrative Atlas, Hanoi.

Illegal mining was called 'looter mining' from the fact that it originally occurred in forms of stealthy mining in forests or on mountains. However, recently, under the loose enforcement and management by the government, illegal mining happens openly everywhere. Formally, illegal mining is understood as mining without permission by an authority (Vietnam Coal and Mineral Corporation or Quang Ninh local government). Hence, theoretically the illegal mined coal shall not have enough source-proving documents. However, through various ways, the illegal coal owners could always have enough file to transport and export those mined coal by 
small ships to China. The main route of their exports is through Van Gia border gate (Mong Cai town) under 'fake documents', or sneaky transportation to big ships, which are readily waiting on the East sea, outside the border.

Figure 2 Map of Quang Ninh province

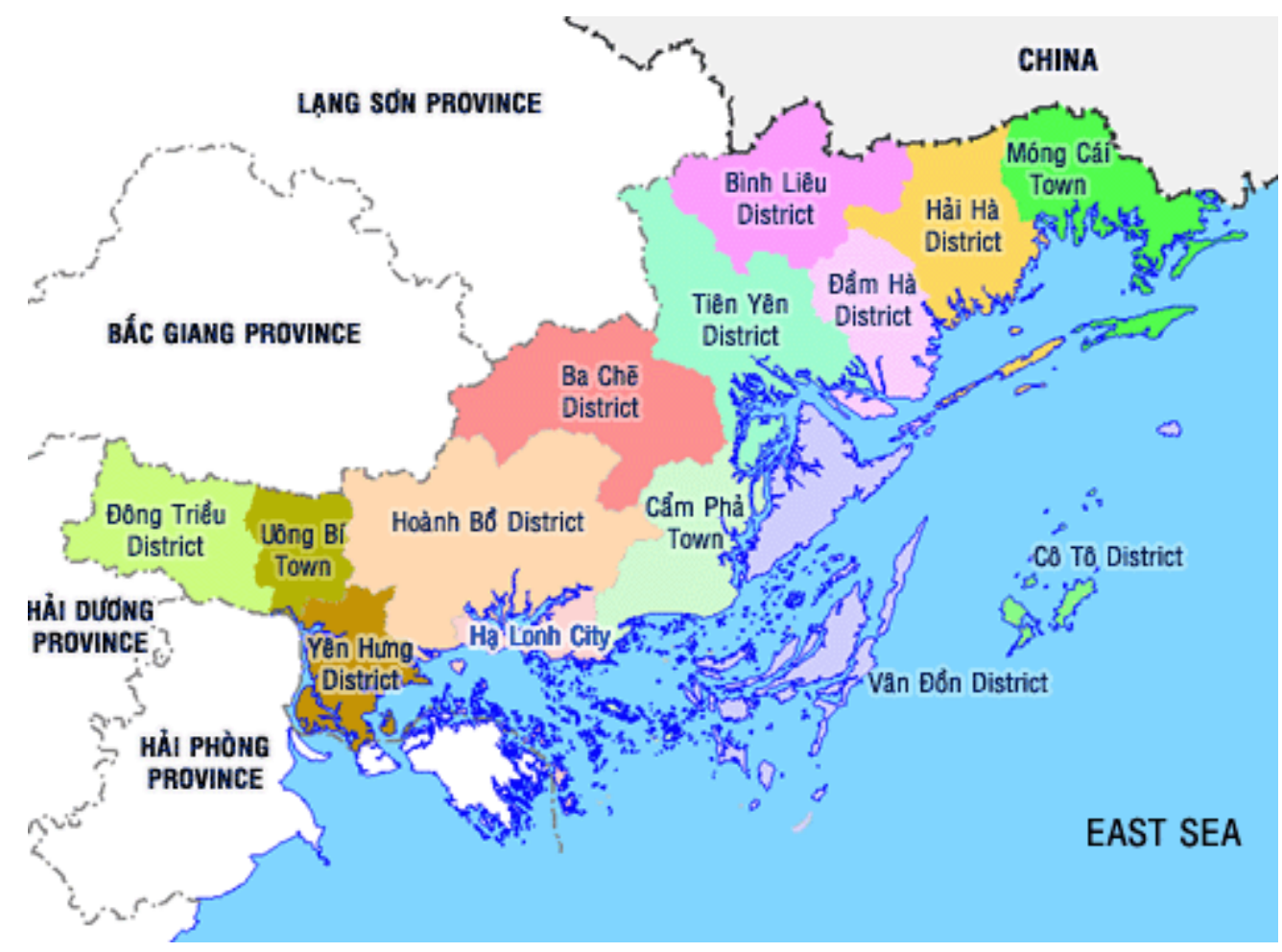

Source: Quang Ninh province committee, 2008. 'Quang Ninh province', http://www.halong.com/halongcom/maps/e_pages/ (01/6/2008)

While the legal mining is well-equipped with strict safety regulations, the illegal mining is under very bad conditions, without necessary safety requirements. The forms of those activities are: (1) digging to take coal anywhere, even beneath houses or in gardens; (2) scraping to take coal from rivers and streams, which drift from legal mining sites; and (3) take coal directly from legal mines through the loose control. Among them, the first form is the most dangerous case. Many illegal miners have died from cellar collapses or water flooded. 
Some houses have fallen because of empty dug foundation. Moreover, illegal mining without any reversal to the original status have caused serious consequences to the surrounding environment.

Figure 3 Some pictures about the unsafety of illegal coal mining
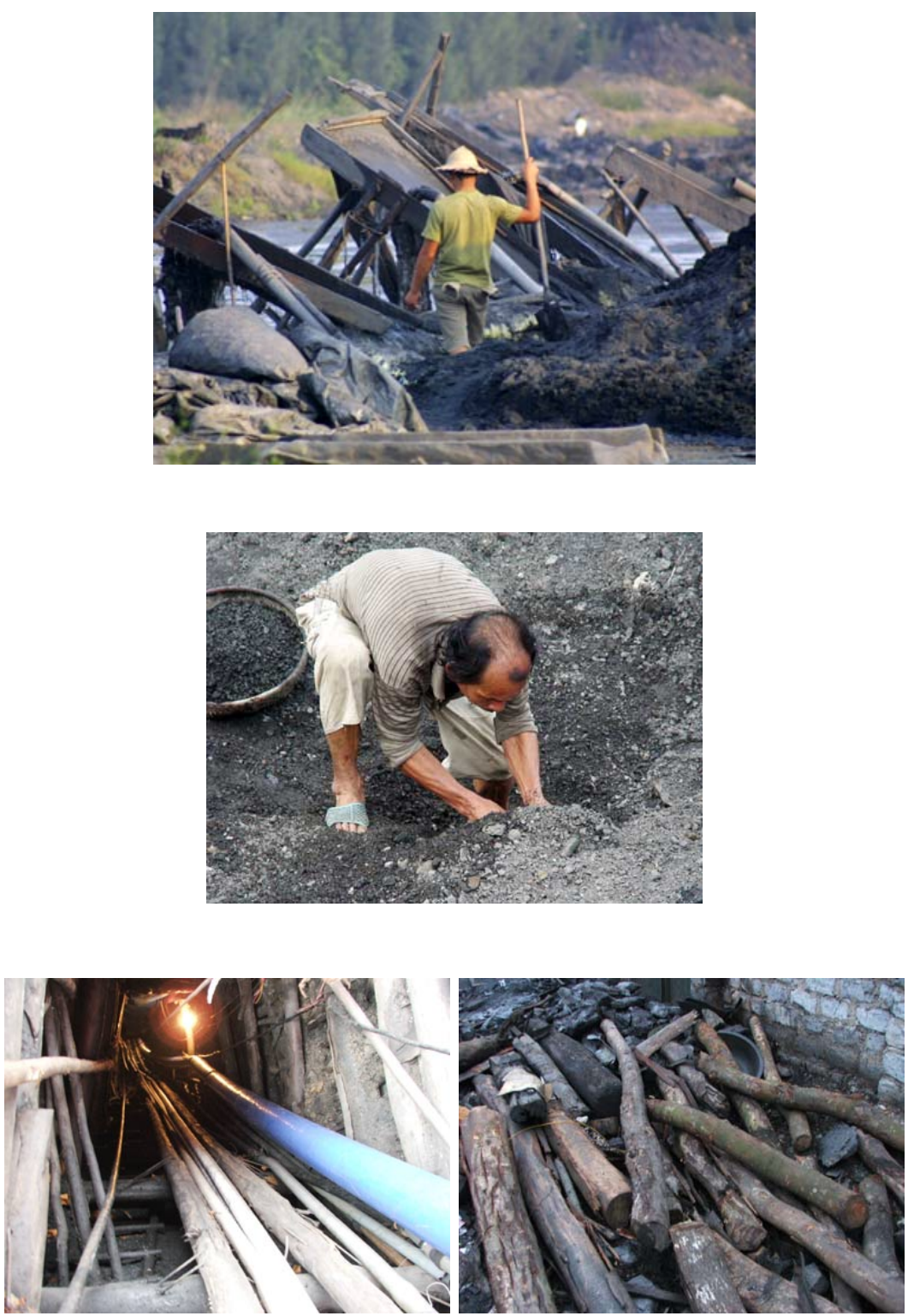

Source: 'Black gold' still flows through border, http://vietnamnet.vn/xahoi/2008/05/785891/ (28/5/2008) 


\section{Figure 4 Map of Mong Cai town (the main route of illegal coal exports)}

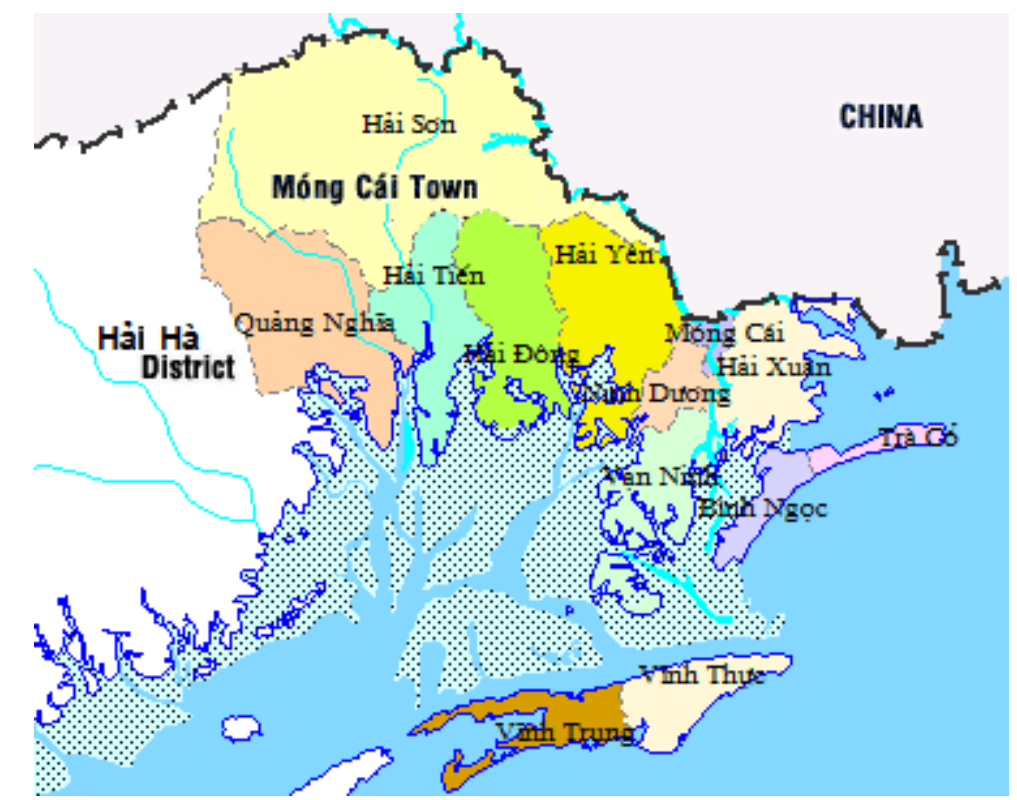

Source: Quang Ninh province committee, 2008. 'Quang Ninh province',

http://www.halong.com/halongcom/maps/e_pages/ (01/6/2008)

As a simulation, this paper aims at constructing a system dynamic model with quantitative scenes. This approach is implemented through two steps. First, we examine the involving factors of the illegal coal mining as happened in Quang Ninh province and build three conceptual models describing the context framework. Then, we construct a detailed model with necessary initial data and quantitatively possible scenarios in order to investigate the dynamics of the system. A discussion of the dynamics modeling tools can be seen in Sterman (2000). The methods are similar to the ones used by Dudley (2004), however we use parts of the actual model with effect-signs instead of standard causal loop diagrams in describing the conceptual models.

All figures are parts of the overall dynamics model. We use a classic style of notations and conventions to label components: stocks are enclosed in boxes (the main stock is in uppercase, 
while the others are in lowercase); flows are in lowercase as hollow arrows with valves; auxiliary variables and constants are also in lowercase. A plus (+) or minus (-) sign on arrows indicates the relationship trend between the two connected variables. Variable and model component names are in italic form when used in the text.

\section{Model structure}

In order to form the main system dynamics model, we construct a basic coal stock model and investigate three interacting loops that describe the following relationships:

(i) Need for income leads to local residents' willingness to engage in illegal mining and attract labors from surrounding provinces to work illegally.

(ii) The efficiency levels of the government's enforcement and coal management affect the illegal mining.

(iii) Some other effects on illegal mining: the density effect, technology effect, community and psychological effects from unsafety.

We start with the basic simple coal stock model. Coal stock - the main stock of interest takes the initial value of 6500 million tons (or 6.5 billion tons as referred above). The inflow is reasonably zero while there are two outflows. First is Legal mining, which is simply set to a constant of 40 million tons per year. The second outflow is the one of consideration - Illegal mining - on which affected factors are examined in this paper. 


\section{Figure 5 Basic coal stock model}

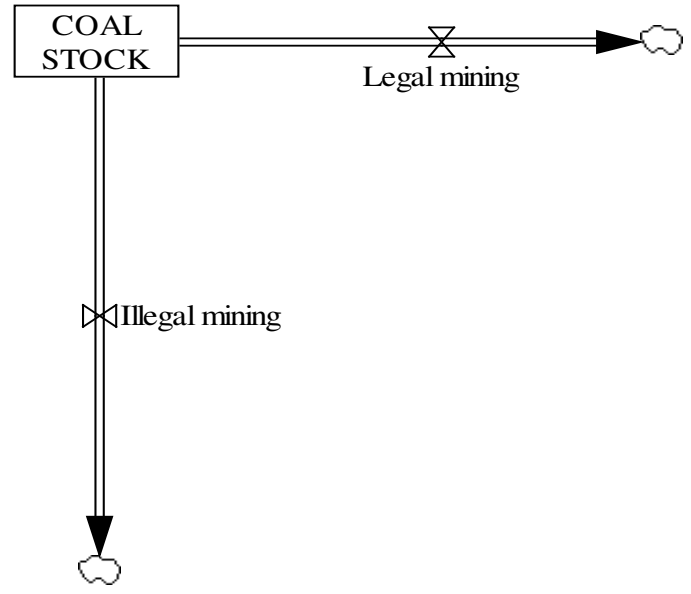

The first interacting loop describes the effects of income need on illegal mining. The illegal workers are divided into two separate groups: local residents, of whom the income effects are more complicated, and non-residents, for whom the only source of income is from the illegal mining. Each group has increase and depreciation rates.

For the first group, the willingness of local residents to mine illegally depends on desired income ratio, but in a quadratic form with the sense that the residents have choices rather than engaging in illegal mining, and they will withdraw from the mining when their desired income reaches a certain level. The income from legal sources is simply set to $500 \mathrm{USD} / \mathrm{year}$ from their residence (such as gardening or opening small shops), while the desired income is 2000 USD/year (which is 1800 for non-resident worker). The income from illegal mining is set to the average of 1200 USD/year initially and increased by 0.1 per cent per year (until the coal stock collapses). Those numbers are somewhat related to 'real income', hence they change very slightly over time. 


\section{Figure 6 Income effect}

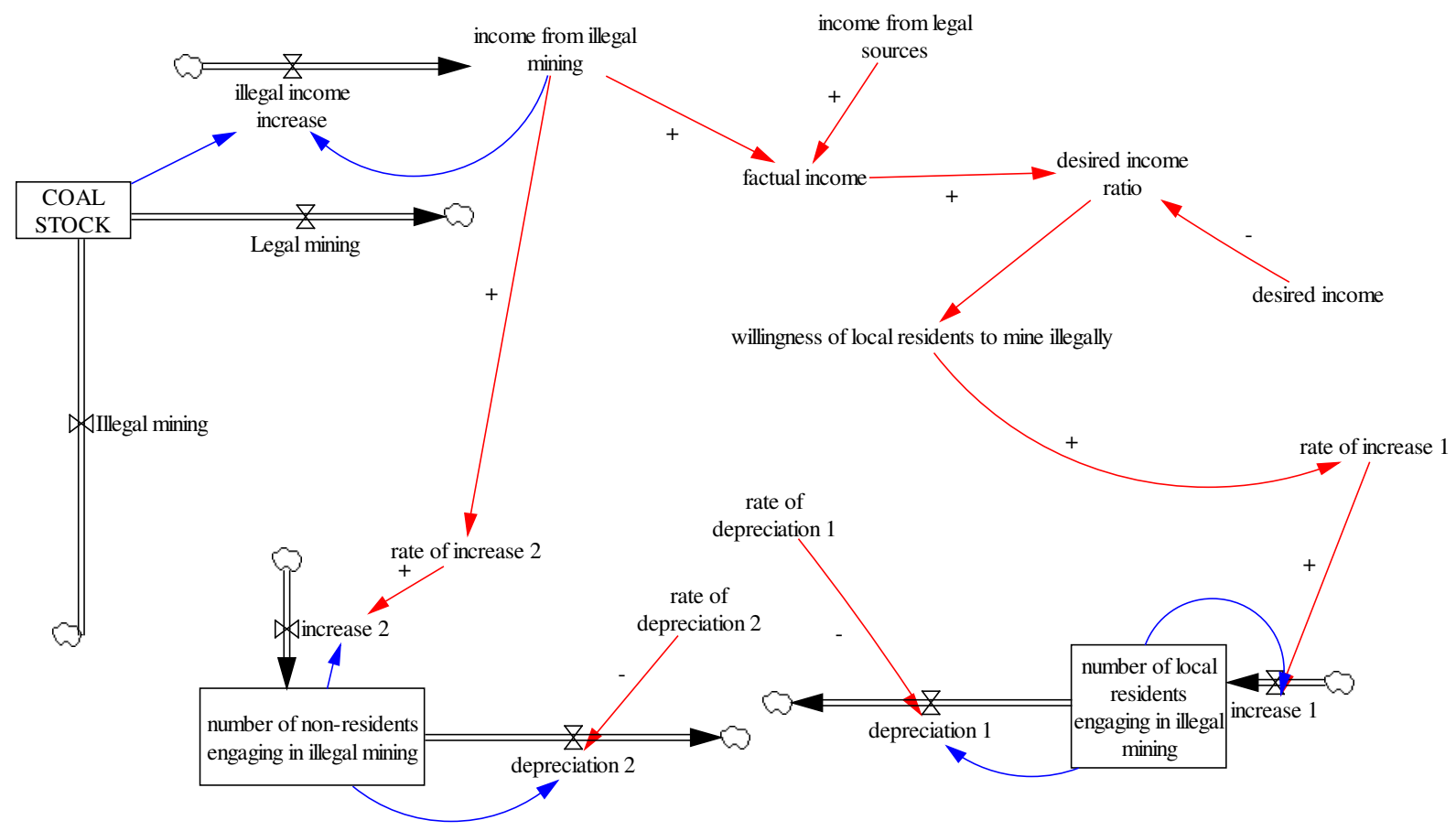

The second interacting loop indicates the effects of the government's enforcement against illegal mining and the efficiency of coal management, which are responsibility of Vietnam Coal and Mineral Corporation and the local authorities. Those organs can have prevention role in any period of the illegal coal-trading chain, such as mining, transporting, exporting. Police, forest warden, border guard, customs and local committee are the main enforcement bodies. In fact, the low efficiency level in the management and enforcement is one of the key reasons of the illegal mining in Quang Ninh province at the moment. Their operation correlates to chance for illegal mining and chance for illegal distribution (which contains storage, transportation, exports and other possible periods involved). 


\section{Figure 7 Enforcement and management effects}

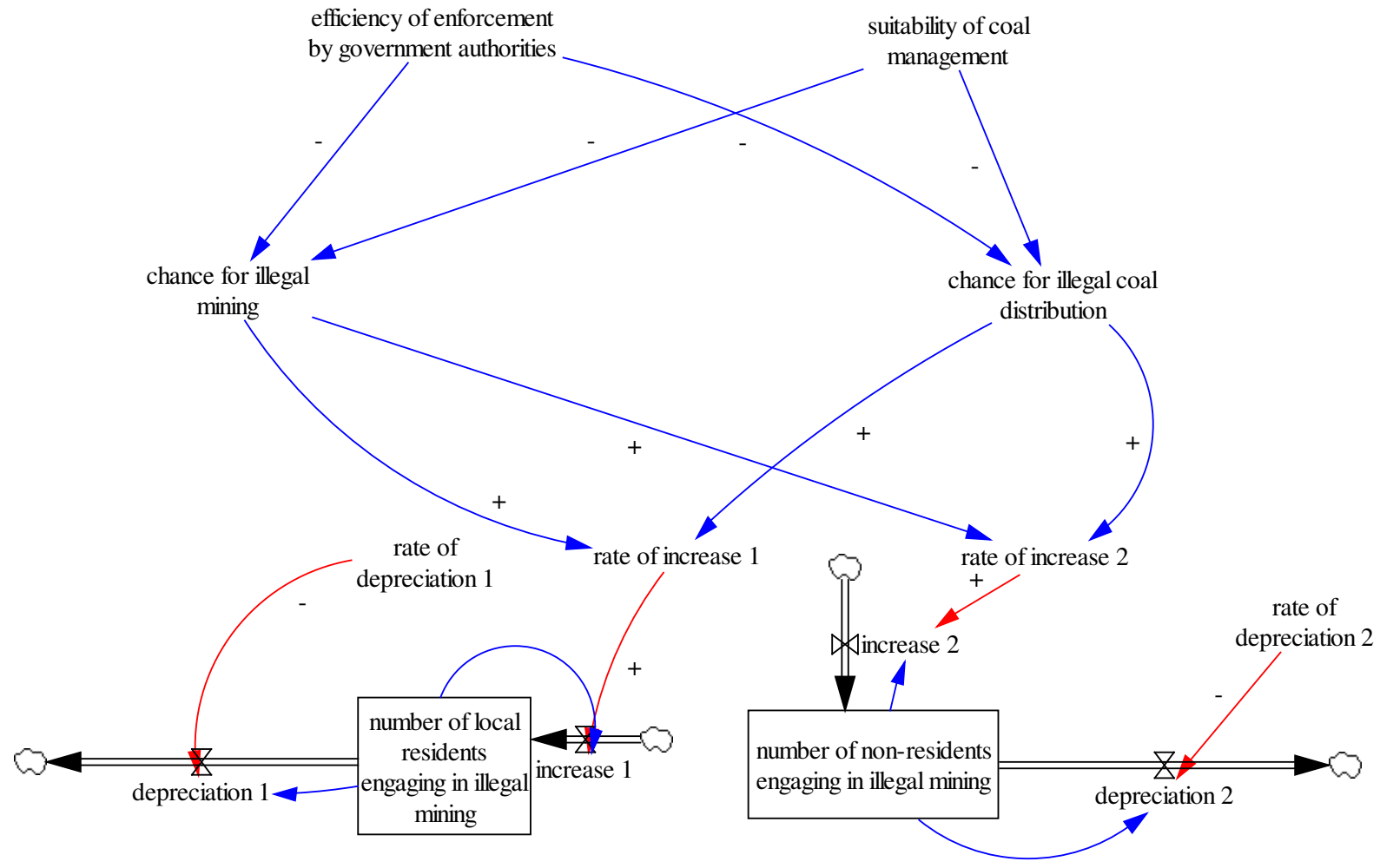

The last interacting loop is to analyze some other effects on the illegal mining rather than income or government effects. A certain level of illegal mining density shall lead to reactions from legally authorized miners to protect their areas of mining and their profits. Hence, the density, which is corresponding to the illegal/legal ratio, would rationally lead to depreciations. In addition, the community effect (can be easily described as the objection of households who are badly influenced by environmental impacts occurred from illegal mining) and psychological effect (which is represented as labors' fears from the horrible unsafety of illegal mines) could have huge affects on the willingness of illegal workers.

Furthermore, the average mining amount of illegal worker may increase over time by technology changes. Nevertheless, because of the illegality of the activities, the mine owners 
would rarely invest in expensive technologies or safety equipments, which may be seized at any time discovered by police or local committee. Finally, the whole depreciation will happen if the coal stock totally collapses.

Figure 8 Other effects

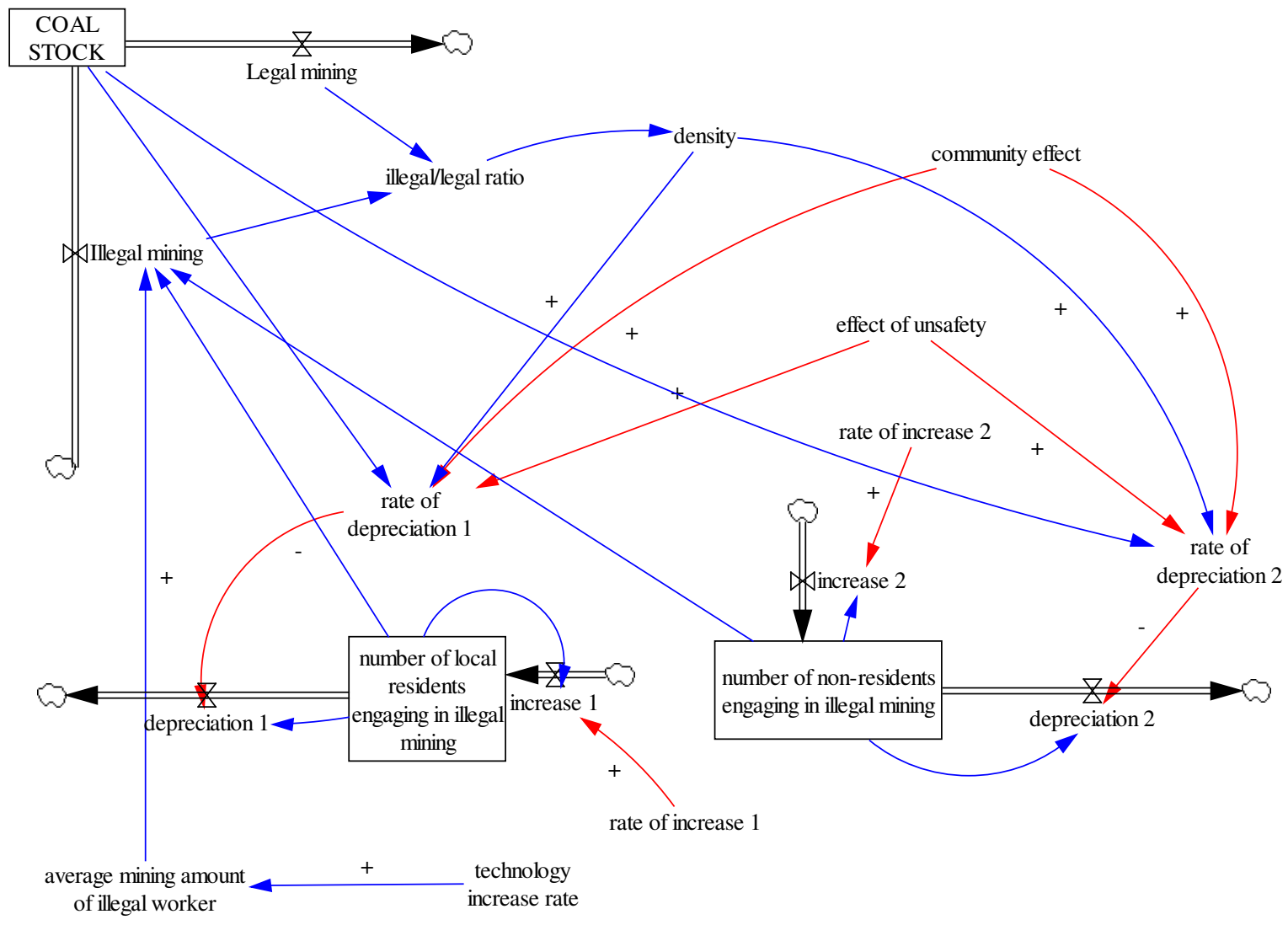

With a notice that many factors seem to have effects on both increase and depreciation, we simplify this by taking out the more indirect effects. From the four above models and loops, we combine and build the 'part of factual model' which is drawn in Appendix A. The detailed equations and setups are described in Appendix B. 


\section{Simulation results and discussion}

We start analyzing possible scenarios by setting the theoretical case with legal mining of 40 million tons per year and without any illegal mining. The maximum existing time of the coal stock will be 162.5 years (till the year 2171). Therefore, the final time of the dynamics model is defined by 200 years. Now we examine the second case where the illegal mining is simply 10 million tons per year without any change, the time reduces to 130 years, 32.5 years earlier.

\section{Figure 9 Two cases: no illegal mining or illegal mining of 10 mil. tons}

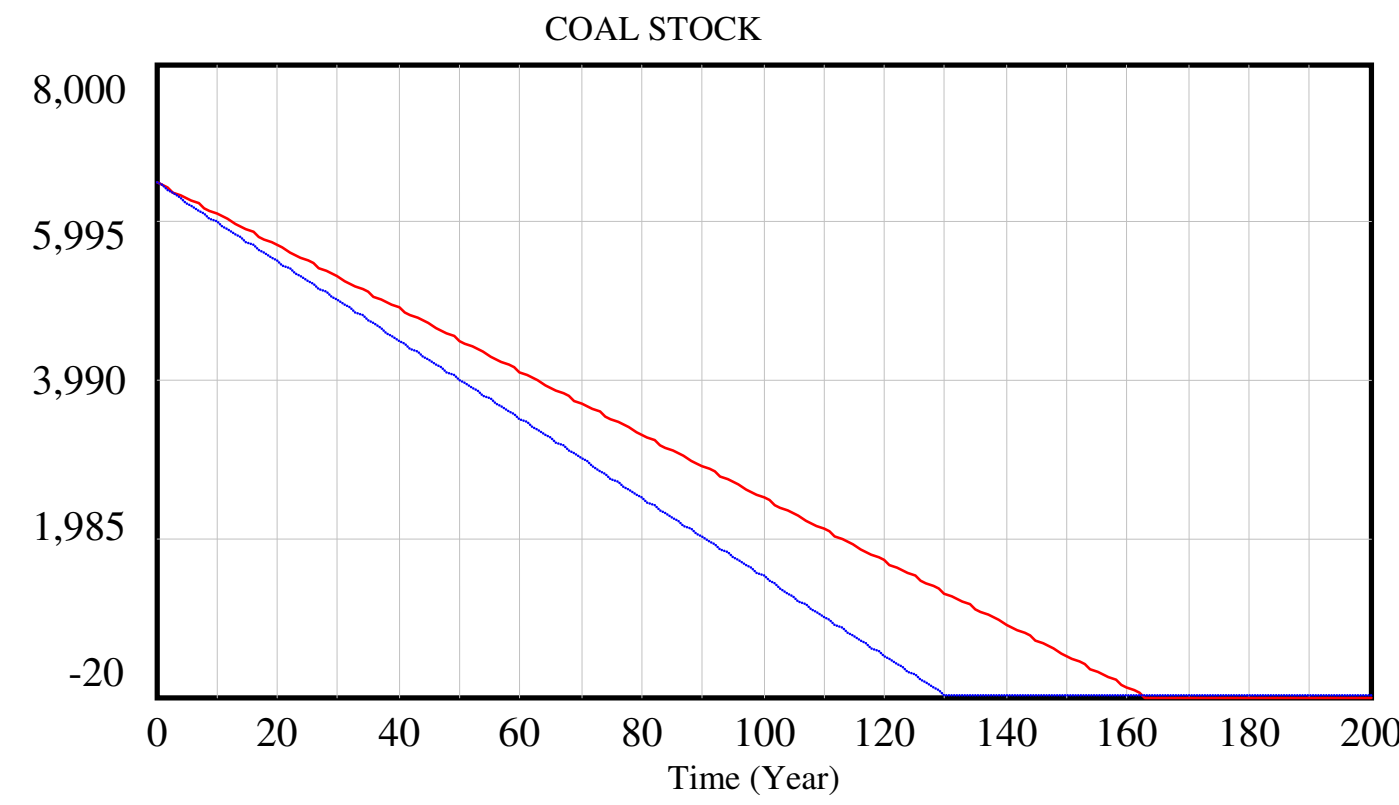

COAL STOCK : Illegal10

COAL STOCK : No illegal

Basing on the actual estimates, the initial number of local residents engaging in illegal mining is set to 30,000 and the number of non-residents engaging in illegal mining is 20,000, most of who come from some neighbor provinces in Red river delta such as Thai Binh, Hai Duong, Hung Yen and Nam Dinh. The average mining amount of illegal worker is about 200 tons per year, in the condition of manual activities (see Figure 3 for a visual example). This amount is 
to be increased by a technology change of 0.1 per cent per year (a fairly low rate as discussed above).

The most important effect is from the efficiency level of government enforcement and coal management. To examine the effect, we keep a correlation between the two variables: efficiency of enforcement by government authorities and suitability of coal management with an implication that an increase in one variable shall require an equivalent increase in the other. Therefore, we simplify the assumption by setting those two variables at the same level. The initial level is simply estimated to be 60 per cent (0.6), then we plug in different values for the two key variables to investigate the changes in coal stock. Different scenarios are described in Figure 10, while the collapsing time is listed in Table 1.

Figure 10 Scenarios under different levels of enforcement and management

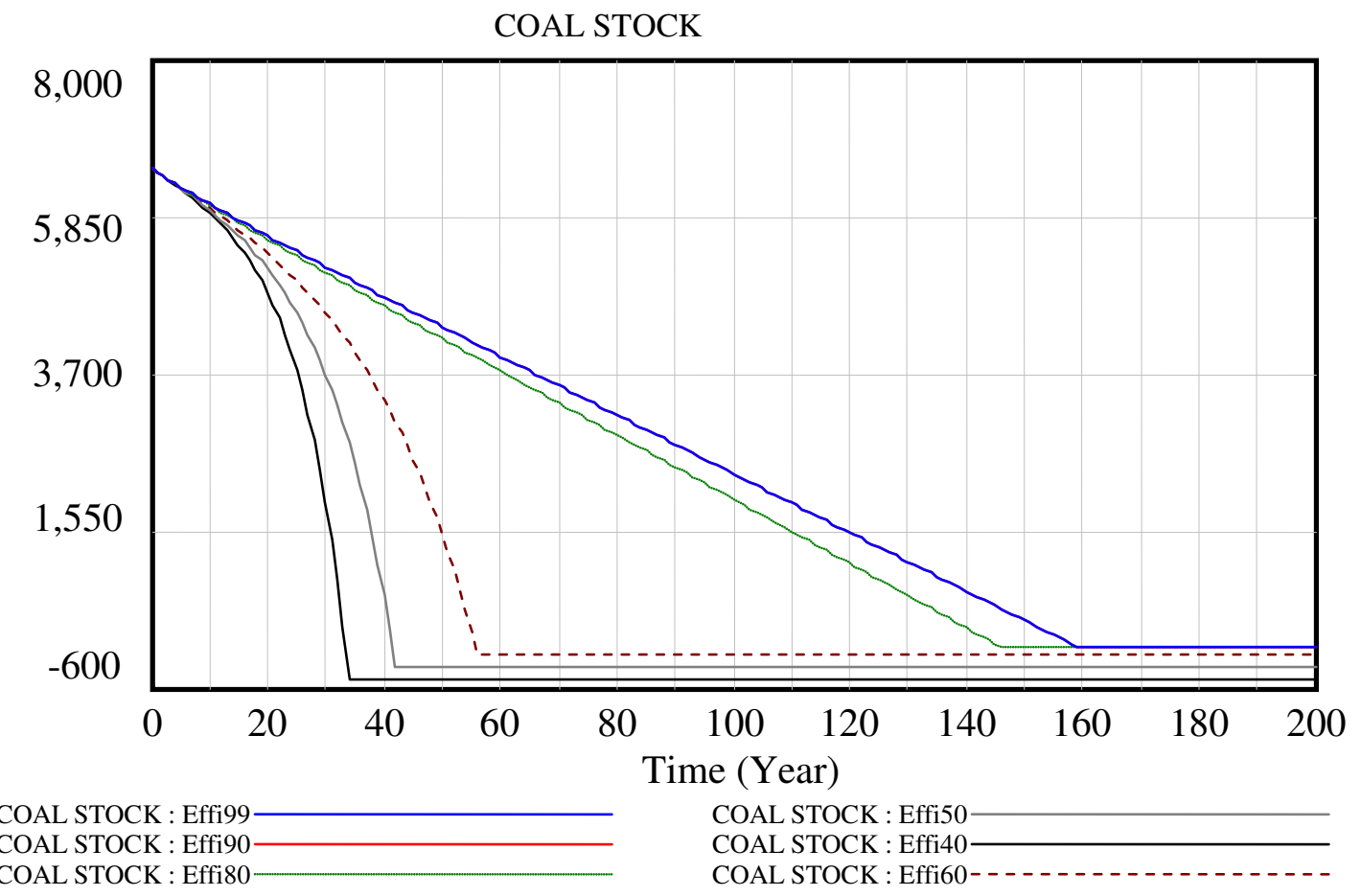


In terms of coal stock, the differences from changes in the level of enforcement efficiency and management are very large. In case of maintaining a level of 60 per cent of efficiency (and the same to management), the coal stock will collapse after 56 years, 106.2 years earlier than the theoretical case - a very substantial number! Even much worse if the efficiency reduces to 40 per cent, the coal stock will be totally exhausted in only 34 years. In contrast, if the government and authorities raise the efficiency of enforcement and management to 90 per cent, the stock will be maintained almost as the maximum case (3.5 years earlier).

Moreover, in terms of the number of illegal workers, including residents and non-residents, the differences are even more impressive. The bad enforcement and management will encourage more than 3.7 million people to engage in illegal mining (3.5 times larger than the current population of Quang Ninh province). This huge number leads to a correlatively massive consequence in economic, environmental and especially social aspects, in which the unsafety, the complication occurred for control and the unintended migration are examples of very serious externalities. Conversely, the good management and implementation will prevent almost all illegal activities. A small notice is that the real number of people engaging in illegal mining may never be zero because of the fact that, from the ease of coal mining, some poor people likely still mine by themselves to supply some small household's demands with cheap price.

Another notice is that the residents start with a number of 30,000 (more than 20,000 of nonresidents), but will always end up with smaller group in comparison to the non-residents. This can be explained that the residents have more choices to do, rather than attending in the illegal mining, and they will have easier chance to get another job, hence they likely withdraw from 
the illegal activities when the illegal mining becomes more difficult. That happens when the illegal density reaches a certain level, or in case of higher enforcement and management.

Table 1 Collapsing time and number of workers under different scenarios

\begin{tabular}{ccccc}
\hline $\begin{array}{c}\text { Efficiency of } \\
\text { enforcement and } \\
\text { Suitability of coal } \\
\text { management (per }\end{array}$ & $\begin{array}{c}\text { Time of } \\
\text { collapse } \\
\text { cent) }\end{array}$ & $\begin{array}{c}\text { Number of } \\
\text { illegal local } \\
\text { residents }\end{array}$ & $\begin{array}{c}\text { Number of } \\
\text { illegal non- } \\
\text { residents }\end{array}$ & $\begin{array}{c}\text { Total number of illegal } \\
\text { workers at the collapse } \\
\text { time }\end{array}$ \\
\hline 40 & 34 & $1,279,590$ & $2,431,980$ & $3,711,570$ \\
50 & 42 & 683,568 & $1,758,, 660$ & $2,442,228$ \\
60 & 56 & 247,094 & $1,091,170$ & $1,338,264$ \\
80 & 146 & 89 & 19,243 & 19,332 \\
90 & 159 & 0 & 31 & 31 \\
99 & 159 & 0 & 31 & 31 \\
\hline
\end{tabular}

Figure 11 Change in number of local residents engaging in illegal mining

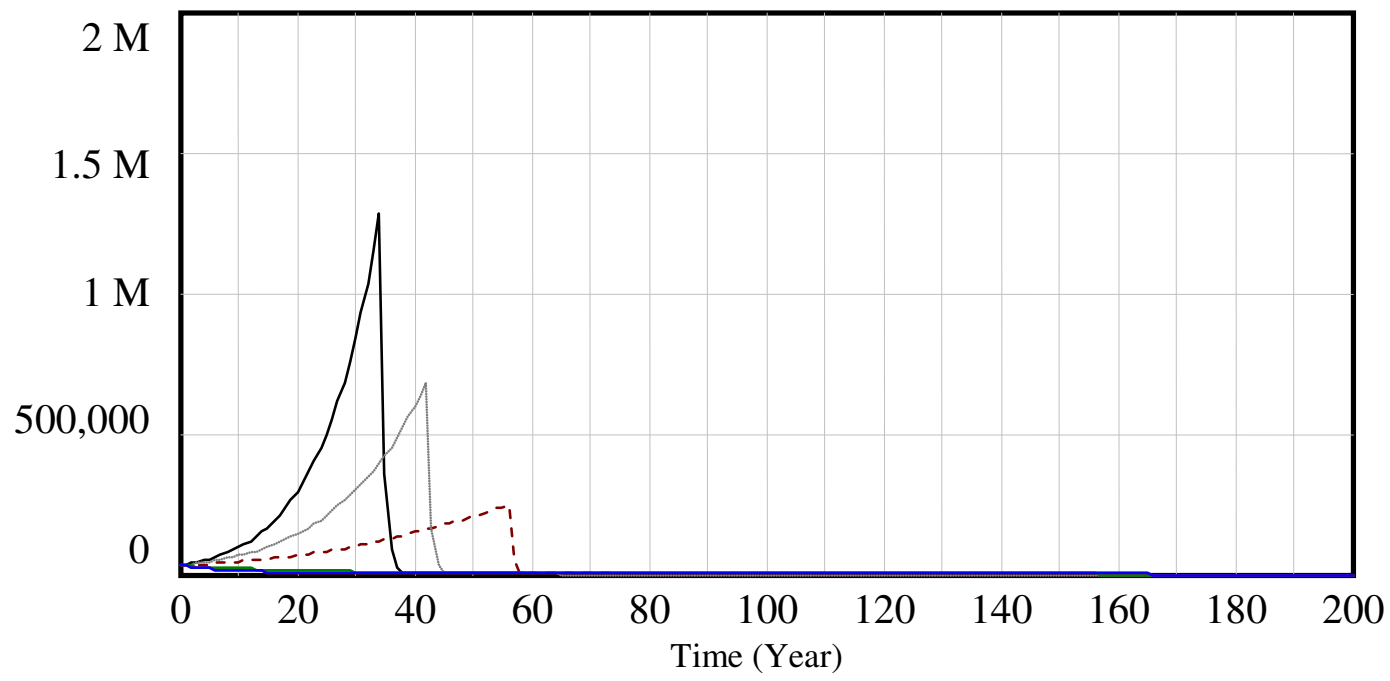

number of local residents engaging in illegal mining : Effig9 number of local residents engaging in illegal mining : Effig 9 number of local residents engaging in illegal mining : Effiof number of local residents engaging in illegal mining : Effi50 number of local residents engaging in illegal mining : Effi 4 number of local residents engaging in illegal mining : EffiGo- 


\section{Figure 12 Change in number of non-residents engaging in illegal mining}

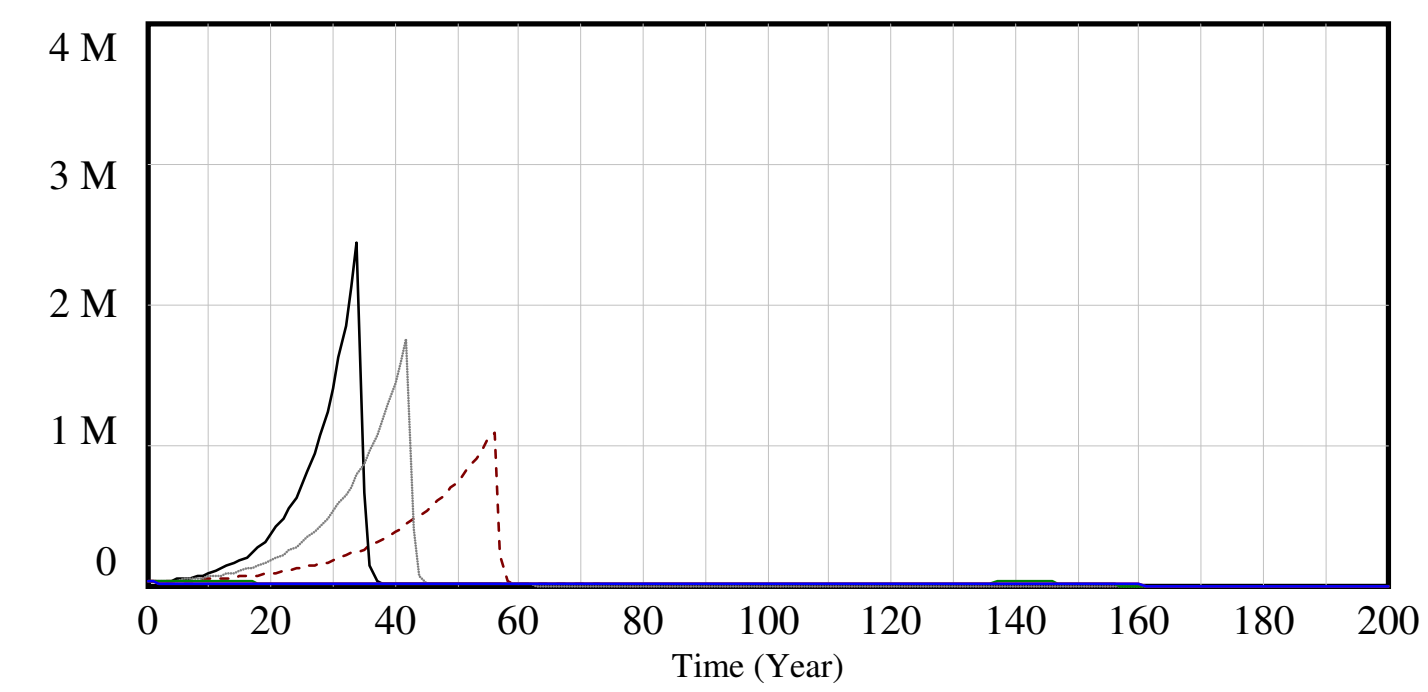

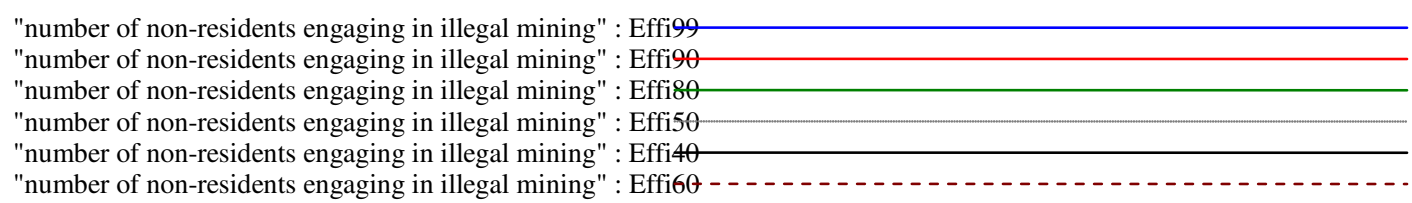

In a similar manner, we examine the effects of community rights and psychological fear (mainly from the unsafety of illegal mining) by setting community effect and effect of unsafety at different levels. Here again, the two variables are seemingly correlated in the scene that, if the community (including mass media) propagandizes and protests actively and effectively, the psychological effect should also be raised. The default value for both is 80 per cent (however the real effects which influence the illegal workers are relatively much lower, because those are just indirect effects and those need a simultaneously strong enforcement to take effectively impacts on labors). Figure 13 describes different scenarios under different levels of community effect and effect of unsafety, holding enforcement and management constant at 60 per cent. The result shows that, though less than the direct effects (enforcement and coal management), the community and psychological effects also play very important 
roles in preventing the illegal coal mining. This also implies that the current activities of community are not enough. The enforcement can compulsorily stop the 'looter mining', and the community can further stop it 'from inside' by abolishing all illegal actions.

Figure 13 Community and Unsafety effects

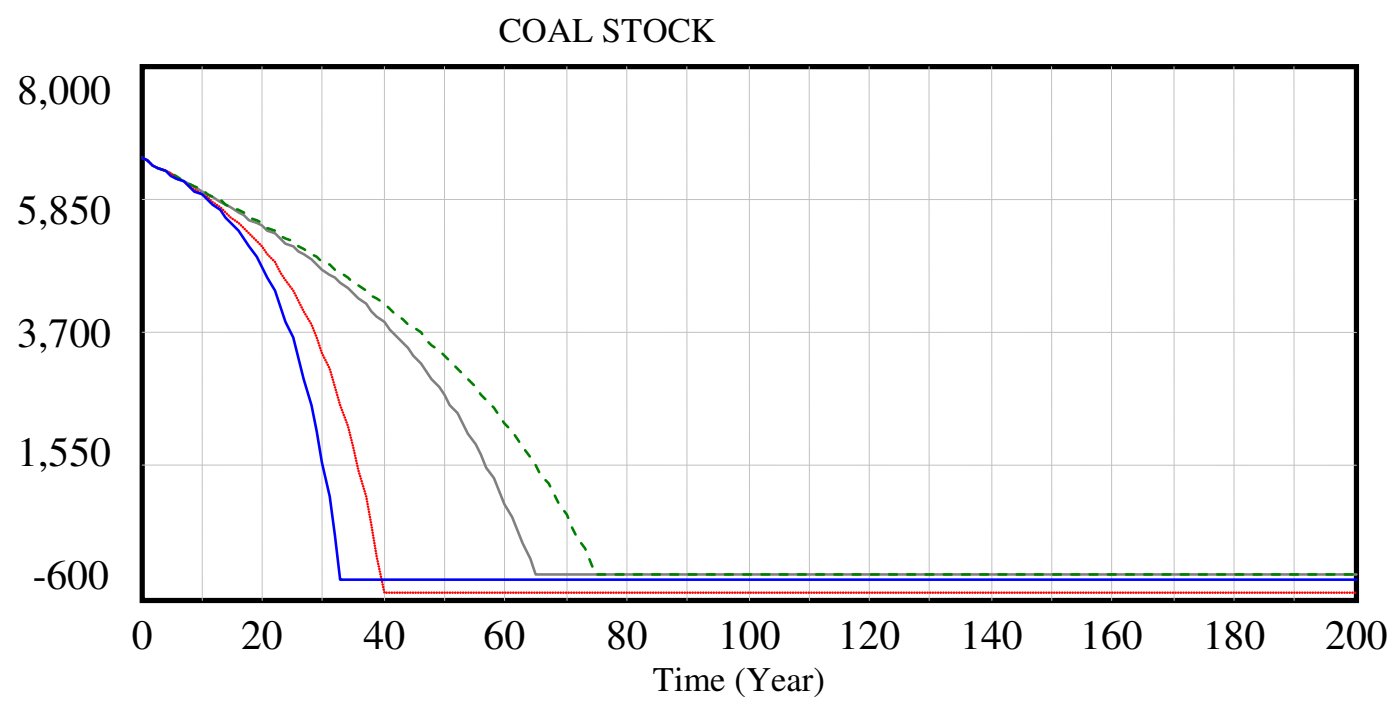

COAL STOCK : commu30

COAL STOCK : commu50

COAL STOCK : commu99

COAL STOCK : commu90

\section{Conclusion}

Using Vensim PLE, this paper provides a simulation of the illegal coal mining in Quang Ninh province, Vietnam. Examining the three main loops including need for income effect, government enforcement and coal management effects and other effects (illegal density, technology, community and psychological effects), the paper sketches several scenarios under different levels of the key variables. Those scenarios show the large differences in terms of stock collapsing time and number of workers engaging in illegal mining. 
Obtaining these results, we suggest a better scene in terms of socio-economic and environmental sustainability basing on the two major components. First, the government authorities, including police, forest warden, border guard, customs and local committee should urge the enforcement against illegal coal mining and distribution. Simultaneously, the Vietnam Coal and Mineral Corporation should rapidly revise the coal management tools in order to prevent illegal forces from taking unfair advantages. Second, the community should have more activities to abolish the illegal mining trend and raise necessary warnings about the danger of the illegal mining. Those parallel implementations shall create a surprisingly positive effect on the prevention of illegal coal mining in the province.

With a limitation of actual data and information, the paper does not contain many analyses on the practical activities in terms of each related sides, especially the illegal coal mine owners. In order to simplify the model at a reasonable level of clarification, we do not put many detailed factors into the model. Therefore, further research can be conducted basing on more data and detailed information in order to build up a broader system dynamics model, which is better in reflecting the real situation of illegal coal mining in the main coal exploitation area of Vietnam. 


\section{Appendix A Detailed system dynamics model}

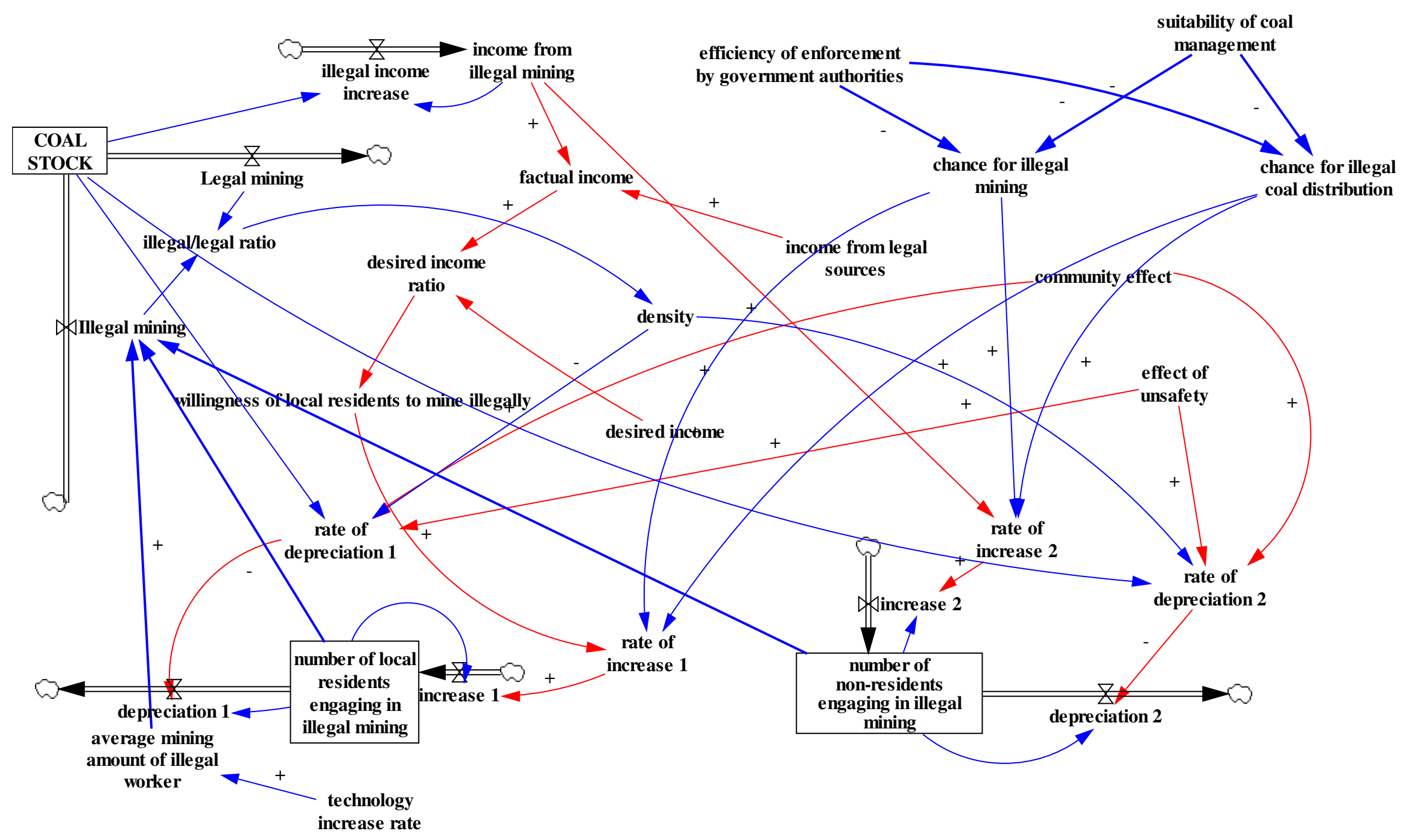




\section{Appendix B Detailed documents of the dynamics model}

(01) average mining amount of illegal worker= INTEG (average mining amount of illegal worker*technology increase rate,0.0002)

(02) chance for illegal coal distribution=IF THEN ELSE(efficiency of enforcement by government authorities+suitability of coal management $<1.8,1.8$-efficiency of enforcement by government authorities-suitability of coal management,0)

(03) chance for illegal mining=IF THEN ELSE(efficiency of enforcement by government authorities+suitability of coal management $<1.8,1.8$-efficiency of enforcement by government authorities-suitability of coal management,0)

(04) COAL STOCK= INTEG (IF THEN ELSE(COAL STOCK>0, -Illegal mining-Legal mining,0),6500)

$[0, ?]$

(05) community effect $=0.8$

(06) density=IF THEN ELSE("illegal/legal ratio">=3, 0.1 , 0 )

(07) depreciation $1=$ number of local residents engaging in illegal mining*rate of depreciation 1

(08) depreciation 2="number of non-residents engaging in illegal mining"*rate of depreciation 2

(09) desired income $=2000$

(10) desired income ratio= factual income/desired income

(11) effect of unsafety $=0.8$

(12) efficiency of enforcement by government authorities $=0.6$

(13) factual income=income from legal sources+income from illegal mining

(14) FINAL TIME $=200$

Units: Year

The final time for the simulation.

(15) illegal income increase=IF THEN ELSE(COAL STOCK >0, 0.001*income from illegal mining, $-1 *$ income from illegal mining)

(16) Illegal mining=(number of local residents engaging in illegal mining + "number of nonresidents engaging in illegal mining")*average mining amount of illegal worker 
(17) "illegal/legal ratio"=Illegal mining/Legal mining

(18) income from illegal mining= INTEG (illegal income increase,1200)

(19) income from legal sources $=500$

(20) increase $1=$ number of local residents engaging in illegal mining*rate of increase 1

(21) increase $2=$ "number of non-residents engaging in illegal mining"*rate of increase 2

(22) INITIAL TIME $=0$

Units: Year

The initial time for the simulation.

(23) Legal mining=40

(24) number of local residents engaging in illegal mining= INTEG (+increase 1-depreciation $1,30000) \quad[0, ?]$

(25) "number of non-residents engaging in illegal mining"= INTEG (0+increase 2depreciation 2,20000$) \quad[0, ?]$

(26) rate of depreciation 1=IF THEN ELSE(COAL STOCK $>0,0.1 *$ (community effect+effect of unsafety+density),1)

(27) rate of depreciation $2=$ IF THEN ELSE(COAL STOCK $>0,0.1 *(0.6 *$ community effect $+0.8 *$ effect of unsafety+density),1)

(28) rate of increase $1=0.1 *$ (willingness of local residents to mine illegally+chance for illegal mining+chance for illegal coal distribution)

(29) rate of increase $2=0.1 *$ (income from illegal mining/1800+chance for illegal mining+chance for illegal coal distribution)

(30) SAVEPER = TIME STEP

Units: Year [0,?] The frequency with which output is stored.

(31) suitability of coal management $=0.6$

(32) technology increase rate $=0.001$

(33) TIME STEP = 1

Units: Year $[0, ?] \quad$ The time step for the simulation.

(34) willingness of local residents to mine illegally $=1.8 *$ desired income ratio-desired income ratio $^{\wedge} 2$ 


\section{References}

Baland, J.M. and Platteau, J.P., 1996. Halting Degradation of Natural Resources, New York.

Cartographic Publishing House, 2005. Vietnam Administrative Atlas, Hanoi.

Dudley, R., 2004. 'A system dynamics examination of the willingness of villagers to engage in illegal logging', Journal of Sustainable Forestry, The Haworth Press, 19(1/2/3):31-53.

Fernandez, J.M., Selma, M.A.E., Aymerich, F.R., Saez, M.T.P. and Fructuoso, M.F.C., 2005. 'Aquatic birds as bioindicators of trophic changes and ecosystem deterioration in the Mar Menor lagoon (SE Spain)', Hydrobiologia 550:221-235.

Grafton, R.Q., Adamowicz, W., Dupont, D., Nelson, H., Hill R.J. and Renzetti, S., 2004. The economics of the environment and natural resources, Blackwell, Oxford.

Palmer, C.E., 2001. The extent and causes of illegal logging: an analysis of a major cause of tropical deforestation in Indonesia, CSERGE working paper, Centre for social and economic research on the global environment, University College, London.

Quang Ninh province committee, 2008. 'Quang Ninh province', http://www.halong.com/halongcom/maps/e_pages/ (01/6/2008).

Simpson, R.D., Toman, M.A. and Ayres, R.U., 2005. Scarcity and growth revisited natural resources and the environment for the new millennium, Washington.

Sterman, J.D, 2000. Business dynamics: systems thinking and modeling for a complex world, Boston.

Sterner, T, 2003. Policy instruments for environmental and natural resource management, Washington.

Ventana Systems Inc., 2007. Vensim user's guide version 5, Harvard.

Vietnam Coal and Mineral Corporation, 2007. Report on coal mining in Vietnam, Hanoi. 